\title{
Research on the Coordinated Development of Higher Education in Lanxi in the Era of Popularization
}

\author{
Caisi Wei* \\ Qinghai Minzu University, Xining 810007, China \\ *Corresponding author: Caisi Wei, $1010495653 @ q q . c o m$
}

\begin{abstract}
China's higher education has entered the popularization stage, which coincides with the 14th Five-Year Plan and the process of educational modernization. As a "short board" in the development of higher education in the western region, the higher education in Lanxi should accurately understand the basic characteristics of the popularization stage of higher education and firmly grasp new opportunities for future development ${ }^{[1]}$. On the basis of interpreting the development needs and policy opportunities of national higher education in the new era, the government in Lanxi needs to renew school-running ideas, clarify school-running development goals, deepen the reform of school-running system, promote the modernization of higher education governance system, strengthen the cultivation of collaborative ability and the construction of characteristic disciplines in its higher education, improve the quality of personnel training and the social contribution of human resources, as well as run a satisfactory education for the people.
\end{abstract}

Keywords: Era of popularization; Higher education; Lanxi; Coordinated development

Publication date: October 2021; Online publication: October 29, 2021

\section{Introduction}

In 2019, the gross enrollment rate of higher education in China has reached $51.6 \%$, marking the popularization of higher education in China. This also means that China's higher education has successfully achieved the three-stage "leap-forward" transformation from elitism to popularity and then to popularization. This does not only include a quantitative increase in the gross enrollment rate of higher education, but also a qualitative change in its system. The coordinated development of higher education does not only promote optimal allocation of higher education resources among regions, expand the sharing scope of high-quality resources in the region, and broaden the development space of regional universities, but also help to improve the overall quality and influence of higher education in the region ${ }^{[2]}$. At present, there are still many shortcomings in both quantity and quality of colleges and universities in Lanxi. Therefore, there is a need to integrate higher education resources, reform the system and mechanism of running colleges and universities, create higher education advantages in Lanxi, and realize the coordinated development of higher education in Lanxi. Based on the era of popularization, this article attempts to explore the coordinated development of higher education in Lanxi.

2. Basic characteristics of universal higher education and the current situation of higher education development in Lanxi

\subsection{Basic characteristics of universal higher education}

With the popularization of higher education, the four new basic characteristics of higher education which 
include diversification, learning, individualization, and modernization have become increasingly prominent

[3]. They are different from the basic characteristics of the elite and popular stages.

First, with the popularization of higher education, the most basic and important feature is diversification. Higher education has changed and diversified in terms of its quality and development. Second, under the influence of the internet and intellectualization, the constraints of time and space have been broken, the characteristics of learning are remarkable, and college students' learning is no longer confined to learning in classrooms or learning at schools. Third, the individualization of personnel training and the respect for students' individual development have helped each student to tap into their own advantages and grow into a useful member of the society. Finally, after entering the stage of popularization, the modernization of higher education has higher requirements for the governance and management of higher education. This requires leaders at all levels of higher education to continuously improve their management ability and governance level.

\subsection{Current situation of higher education development in Lanxi}

The gross enrollment rate of higher education in China has been increasing, from $40.0 \%$ in 2015 to $51.6 \%$ in 2019, and the total number of students has reached 40.02 million with the largest higher education system in the world. In 2018, the gross enrollment rate of higher education in China reached $48.1 \%, 58.3 \%$ in Jiangsu Province, $49.1 \%$ in Shanxi Province, and 43.36\% in Qinghai Province, but only 37\% in Gansu Province. As early as 2008, Jiangsu Province has reached 38\%. According to the provincial distribution of A-type disciplines in the fourth round of discipline evaluation by the Ministry of Education, the proportion of A-type disciplines in the eastern, central, and western regions is $70.72 \%, 19.99 \%$, and $9.29 \%$, respectively, with obvious differences among the three regions. As far as the provinces in the western region are concerned, the total number of A-type disciplines in Sichuan and Shaanxi provinces has reached more than 20. On the other hand, the number of A-type disciplines in Gansu Province is 2, and the number of Atype disciplines in Qinghai Province is 0. This, to some extent, reflects the lagging development of higher education in the western region ${ }^{[4]}$. Gansu Province and Qinghai Province are weak links of higher education in the western region. They do not only affect the overall social and economic development in Lanxi but also restrict the fairness of education, the overall development of higher education, and even the construction of a modern and powerful country to a certain extent ${ }^{[5]}$.

\section{Challenges and opportunities for the development of higher education in Lanxi in the popularization stage}

\subsection{Flawed structure in the higher education system}

The most basic characteristic of the popularization stage of higher education is diversification, which is not only manifested in the diversification of higher education objects and organizational structures, but also in the development of various forms of higher education, such as public, private, adult, and continuing education, as well as the construction of a sound lifelong education system ${ }^{[6]}$. First of all, the current development of Lanxi's higher education system is dominated by public universities. Private colleges and universities are supplements, and there is a huge gap in quality and level between them. Secondly, the development of private colleges and universities in Lanxi started late in addition to its slow speed, small social influence, low recognition, as well as various problems in the development mechanism and environment. In a word, the higher education structure in Lanxi is not complete enough, and a benign ecosystem has not yet been formed. 


\subsection{Unsound cooperative development mechanism for cooperative education}

In Lanxi, due to the influence of ideas, geography, and other factors, the traditional idea of running a school is dominant, and the awareness of opening a school is relatively weak. First of all, the exchanges and cooperation between universities in Lanxi and well-known universities at home and abroad are insufficient. In addition, their international vision of running schools is narrow ${ }^{[7]}$. Secondly, local colleges and universities are not closely linked and cooperated with the government, social organizations, and other organizations. In terms of specialty and curriculum setting, practice base construction, as well as other key links of personnel training, the actual situation of local development has not been fully taken into account in terms of discipline direction, scientific research topics, as well as scientific and technological achievements. Finally, the system for collaborative education and innovative development in Lanxi has not yet been formed, and the benign mechanism of collaborative development between schools and localities is not sound enough. Furthermore, public recognition and social contribution are obviously insufficient.

\subsection{Non-prominent quality and characteristics of running schools}

Under the long-term influence of history and other reasons, there are differences in the quality and level of higher education between the western region and the eastern and central regions. Colleges and universities in Lanxi have shortcomings in personnel training scale, transformation of scientific research achievements, employment of graduates, social services, and so on. Although China's higher education has entered the stage of popularization, the transformation and development tasks of schools have not been completed. In addition, the benign development mechanism has not been formed. The higher education in Lanxi is homogeneous in the setting of disciplines and specialties, mainly in normal education, agriculture and forestry, ethnic, as well as other specialties, lacking individualization, inaccurate positioning, unclear thinking, and convergence of specialty settings. It is difficult to meet the requirements of diversification, individualization, and modernization of universal higher education.

\section{Coordinated development of higher education in Lanxi}

\subsection{Improving the legal guarantee system for the coordinated development of higher education in Lanxi}

Regional higher education cooperation is essentially a consultative administrative act among local governments at the same level. It needs to be regulated and guided by the external legal system as it lacks the essential power restriction relationship ${ }^{[8]}$. Therefore, it is necessary to improve the legal guarantee system for the coordinated development of higher education in Lanxi and enhance the level of coordinated development of higher education in Lanxi. In order to do so, the legal provisions of the cooperative relationship among local governments at the same level can be added to adapt to the development trend of regional economic and social integration as well as promote the coordinated development of higher education in Lanxi. Cross-regional higher education cooperation clauses can also be implemented while clarifying the rights and responsibilities of higher education cooperation among provincial governments to promote the optimization and coordinated development of higher education resources among regions ${ }^{[9]}$. A leading body can be established in Lanxi based on relevant laws and regulations for the coordinated development of the regional economy and society in Lanxi as well as supervise the cooperation of higher education among the governments in real time, so as to promote the cooperative development of higher education in Lanxi.

\subsection{Goal integration to promote the coordinated development of higher education in Lanxi}

At present, high-quality higher education resources are relatively limited in China, and it is not advisable 
to solve this scarcity by expanding the scale in short term. Therefore, in the process of cooperation, the governments in Lanxi should take the coordinated development of regional higher education as a starting point and establish a platform for human resource exchange and cooperation. Other than that, it may be worthwhile to establish a sharing platform of material resources and information network resources, sign cooperation agreements for postgraduate joint trainings, improve the radiation effect of higher education resources in Lanxi, and promote the integration of higher education development goals. In these processes, scientific and reasonable performance appraisal standards are required. Regional intergovernmental cooperation, including higher education collaboration, should be included in the performance appraisal of local officials, so as to stimulate the collaboration behavior among local governments, set a clear orientation for the coordinated development of higher education in Lanxi, and enhance the enthusiasm of intergovernmental cooperation of higher education in Lanxi.

\subsection{Establishing a cross-regional cooperation organization for the coordinated development of higher education in Lanxi}

The establishment of cross-regional cooperation organizations can break the spatial constraints of higher education management system based on traditional administrative divisions and provide an organizational communication platform for higher education cooperation among local governments. Although the planning of Lanxi urban agglomeration has been issued, there would be problems, such as realistic gap and poor planning convergence, from its policy to its implementation. In view of that, Lanxi urban agglomeration urgently needs to establish a scientific and effective cross-regional cooperation system, improve the consultation of interest expression, modify the conflict coordination mechanism, expand the scope of cooperation, formulate a linkage development plan, carry out overall planning and supervision, as well as ensure restraint on the coordinated development of higher education among regions. All these should be based on the clear division of its government's higher education function. According to the implementation of the higher education linkage project, the strategic plan should be adjusted in time, seminars on the coordinated development of higher education in Lanxi should be held regularly, the attraction of talents should be emphasized, and various policy tools should be adopted to ensure the smooth realization of the coordinated policy objectives of higher education in Lanxi.

\section{Disclosure statement}

The author declares that there is no conflict of interest.

\section{References}

[1] Zhong B, Wang X, 2019, China's Higher Education Towards Universalization: Opportunities, Challenges and Prospects. China Higher Education Research, (08): 7-13.

[2] Fang Z, Ou Y, 2016, Regional Coordinated Development of Higher Education and Rational Government Decision-making. Decision and Information, (07): 101-107.

[3] Dong L, 2016, Diversification: The Basic Characteristics of the Stage of Popularization of Higher Education. China Higher Education, (17): 10-11.

[4] Yuan Z, 2019, Revitalizing Higher Education in Central and Western China: The Only Way to the Modernization of Higher Education in China. China Higher Education Research, (11): 5-8.

[5] Wang S, 2017, Facing 2030: Connotation, Characteristics and Construction Strategies of the Modernization of Higher Education System. Heilongjiang Higher Education Research, (11): 19-23. 
[6] Shi Z, 2020, Theoretical Essentials and Practical Requirements of Connotative Development of Higher Education. Journal of National Institute of Educational Administration, (09): 7-15.

[7] Jiang Y, Wu N, Xia H, 2021, Theoretical Framework and Promotion Path of Educational Innovation and Development in Chengdu-Chongqing Economic Circle from the Perspective of Synergy. Contemporary Vocational Education, (03): 10-19.

[8] Chen S, Yang P, 2021, The Value and Path of the Revitalization of Higher Education in the Central and Western Regions from the Perspective of "Double Circulation". Journal of National Institute of Educational Administration, (05): 53-60. 